\title{
LA TRADICIÓN INDIRECTA EN DOS RESTITUCIONES AL TEXTO DEL PSEUDO-CIPRIANO DE LAUDE MARTYRII
}

LAMBERT FERRERES

Indirect tradition as support for the text restitution in two passages of Pseudo-Cyprian's De laude martyrii.

La paráfrasis, como forma velada de alusión, es un procedimiento frecuente en los autores de la tardía latinidad, acorde con la concepción que en la Antigüedad se tenía sobre la creación literaria ${ }^{1}$. Para la crítica textual, el testimonio de este tipo de tradición indirecta no es equiparable, por su misma naturaleza, al que aportan las citas literales. Sin embargo, en algunos casos, su contribución puede resultar fundamental para el establecimiento del texto. Tal sucede, en mi opinión, en dos pasajes del escrito anónimo De laude martyrii (=dlm), del tiempo de san Cipriano o algo posterior, incluido en la mayoría de manuscritos de la tradición ciprianea. Este breve tratado fue editado, entre otros escritos espurios, por W. von Hartel en el apéndice a su edición de la obras del obispo de Cartago ${ }^{2}$. Para la constitución del texto el editor vienés se basa en el testimonio de siete códices antiquiores: dos familias, LNP y MQT, que, en su opinión, remontan a sendos subarquetipos, y S,

1 Sobre esta cuestión me permito remitir a un lúcido artículo que, hace ya bastantes años, publicó H. Hagendahl, «Methods of Citation in Post-Classical Latin Prose», Eranos 45, 1947, pp. 114128.

2 CSEL III, 3, Viena 1871, pp. 26-52. 
el testimonio más antiguo, perteneciente a una tradición independiente. Dos de ellos son incompletos: S sólo transmite la segunda mitad del escrito, desde la p. 39, 3; el texto de $\mathrm{P}$, además de una extensa laguna inicial, que se extiende desde la p. 26, 10 hasta la p. 30, 6, se interrumpe en la p. 45, 13. Para el editor, S es garante del mejor texto y, en su defecto, la preferencia ha de concederse a $\mathrm{LNP}^{3}$.

En el capítulo 3, p. 28, 3-7, se lee:

quantae enim sit gloriae ponderate $<\mathrm{ab}>$ huius uitae cupiditatibus adque ab omni animum natura mundique commercio segregatum contra aduersantis discrimen opponere, nec saeuitiam torquentis horrere, animari hominem nec dolore quo credatur extingui et id sibi in augmentum uirtutis adsumere quod cruciatui putat prodesse qui punit.

En este pasaje, transmitido sólo por los cinco manuscritos que presentan el texto completo, LN presentan la lectura nec dolore, que el editor prefiere, MT dolore y Q dolere. Pero el texto así establecido plantea un problema de interpretación, toda vez que no resulta claro qué elementos coordina este segundo nec. La omisión de la partícula coordinante en el texto transmitido por MT se debe probablemente a un intento de solventar tal dificultad, pues, en efecto, la supresión de nec permite interpretar el ablativo dolore como instrumental de animari. La colación del resto de la tradición anterior al siglo XV revela esta misma lectura en los manuscritos 218b, 331, 100, 419, 252, 253b, 255, 257b, 354b, 234, 216, 110, 200 y 67b; en otros tres, 233, 219b y 435, se lee nec dolere y en uno, 66b, dolere.

Con todo, para la constitución del texto contamos también aquí con el apoyo de la tradición indirecta, cuyo testimonio, en mi opinión, resulta esclarecedor. En el

3 Véase CSEL III, 3, pp. II-VIII, XXIX-XLVI y LX. Salvo en el caso de los siete manuscritos de la edición de Hartel, que se citan por siglas alfabéticas, para el resto de códices utilizo la referencia numérica, cronológico-topográfica, que les atribuye $\mathrm{H}$. von Soden en su fundamental estudio Die cyprianische Briefsammlung. Geschichte ihrer Entstehung und Überlieferung. Leipzig 1904 ("Texte und Untersuchungen", N. F. 10, 3), y también en "Sententiae LXXXVII episcoporum. Das Protokoll der Synode zu Karthago am 1. Sept. 256", Nachrichten von der königlichen Gesellschaft der Wissenschaten zu Göttingen, phil.-hist. Klasse, Berlín 1909, pp. 247-307. Con posterioridad, M.Bévenot (The Tradition of Manuscripts. A Study in the Transmission of St. Cyprian's Treatises, Oxford 1961) amplió el acervo de Soden con algunos manuscritos más y modificó la cronología de otros (lo señalo con una $b$ añadida al número de referencia). La relación de los manuscritos citados figura al final del artículo. 
tratado Moriundum esse pro Dei filio, redactado alrededor del 360, su autor, Lucífero de Cagliari, utiliza profusamente, entre otros, el texto del $\mathrm{dlm}^{4}$. No se trata de citas literales, sino de reelaboraciones insertas en el cuerpo del escrito sin solución de continuidad. En el capítulo 2, 48-56, se lee l: $^{5}$

Vt contra aduersans discrimen duremus stabiles nec saeuitiam tuam torquentis horreamus, animemur magis quam doleamus, ista efficit conscientia quae reminiscitur unicum dei filium ad protegendos uictoresque efficiendos suos suae diuinitatis praebere presentiam; hinc efficitur, ut qua nos credis extingui poena uiuificemur. Id etenim nobis, qui eum propter quem patimur esse nobiscum credimus, in augmentum uirtutis adsumimus, quod tu cruciatui sperasti prodesse, punitor.

La comparación del redactado inicial, desde ut hasta doleamus, con el texto fuente revela un claro paralelismo en la disposición de los enunciados, y también una correspondencia en las formas verbales, excepto en doleamus, que carece de correlato en el texto editado por Hartel: duremus/opponere, horreamus/horrere, animemur/animari, doleamus/... Ello lleva a concluir que en el ejemplar del $\mathrm{dlm}$ que manejaba Lucífero se leía nec dolere, el correlato lógico de doleamus. Esta lectura, que, con toda seguridad, es la correcta, se lee en los manuscritos 233, 219b y 435, pero no aparece transmitida en su integridad por ninguno de los códices utilizados por el editor vienés; sólo Q lee dolere, pero omite nec, al igual que 66b.

La restitución de dicha lectura restablece el equilibrio en la disposición de los dos miembros: opponere nec... horrere, animari... nec dolere, y el pasaje resulta entonces perfectamente comprensible. La disposición bimembre queda además claramente destacada mediante el uso de la misma cláusula $1 \mathrm{~g}$ al final del primer miembro, torquentis horrere, y en la conclusión del segundo, credatur extingui. En la puntuación, la coma que Hartel coloca tras opponere no resulta necesaria y, en cambio, sería recomendable tras extingui, para indicar convenientemente la pausa.

En el capítulo 23, p. 46, 3-5, Hartel establece el texto como sigue:

4 Cf. A. Merk, «Lucifer von Calaris und seine Vorlagen in der Schrift Moriendum esse pro Dei Filio», Theologische Quartalschrift XCIV, Tübingen, 1912, pp. 1-32. Una actualización de las observaciones de Merk a la luz de nuevos pasajes paralelos puede verse en L. Ferreres, «Las fuentes de Lucifer de Cálaris en su Moriundum esse pro dei filio», Anuario de Filología 3, Barcelona, 1977, pp. 104-115.

5 El texto se cita por capítulo y líneas de la edición de G.F. Diercks, CCL 8, Turnhout 1978. 
sic cum arantibus sementa defecerint et herbis terra morientibus aestuarit, supinis e collibus fluuium iuuit elicere et scaturientibus riuis arua sitientia temperare, quo se in uberes culmos uicta agri ieiunitas funderet et pluuiali imbre mentito seges densior inhorreret.

El editor ha desestimado la lectura arentibus de LN en favor de la lección arantibus, transmitida por QMT, manuscritos de inferior calidad, pero concordantes aquí con $\mathrm{S}$, el testimonio más conspicuo de la tradición ${ }^{6}$. Mas el texto así establecido resulta en este punto poco claro y, en cierta medida, hasta incoherente. La lectura arantibus, que prefiere Hartel, es, a mi juicio, el resultado de una corrupción del texto por lectio facilior, propiciada, en parte, por el contexto inmediato, y también por el uso bastante insólito del neutro plural arentia como sustantivo, con el significado de 'sequedal'".

También aquí la tradición indirecta resulta de suma importancia para la constitución del texto. Ahora bien, a diferencia del pasaje anterior, en este caso el dlm es el receptor de una influencia ajena. El anónimo autor del escrito inspira aquí su discurso en los versos 104-110 de la primera Geórgica:

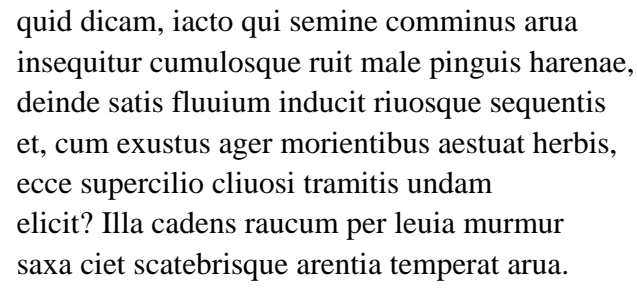

La comparación entre ambos pasajes evidencia que arentibus está tomado de Virgilio. El autor del $d \mathrm{~lm}$ sigue aquí un procedimiento análogo al que se observa en otras paráfrasis del texto virgiliano presentes en el escrito ${ }^{8}$. El hemistiquio arentia temperat arua se convierte, por cambio en el orden de palabras y

6 Carecemos también aquí del testimonio de P, cuyo texto se interrumpe en el capítulo 23, p. 45 , 13. Igual sucede en los manuscritos $126 \mathrm{~b}$ y 203 , estrechamente emparentados con P. En el aparato crítico por error se indica arentibus como lección de T.

7 El ThlL II 504, 68-71 registra este uso a partir del período postclásico: Séneca, dial. 5, 20, 2 y Tácito, ann. 15, 42; ibid. 505, 73-74, como sinónimo de 'madera' en Paneg. 12, 45.

8 Véase al respecto L. Ferreres, "Fuentes clásicas en el Pseudo-Cipriano De laude martyrii", $\cdots$ 
sustitución sinonímica, en arua sitientia temperare y el elemento sustituido, arentia, se inserta, adaptado, al comienzo de la comparación. El uso de arentibus constituye un elemento más del halo virgiliano que envuelve el pasaje y que evoca veladamente los versos del mantuano.

No cabe, pues, duda de que la lectura arentibus, transmitida por los manuscritos LN y también por 100, 419 y 200, es la correcta. La escasa frecuencia que se registra en el uso de arentia como sustantivo explica las adiciones que se observan en buena parte de los manuscritos más recientes: arentibus glebis 233, 331, 234, 219b, 435; arentibus campis 216, 110; arescentibus glebis 252, 253b, 255, 257b, 354b. Estas adiciones tienden a facilitar la interpretación de arentibus supliendo el sustantivo al que supuestamente iría referida la forma participial.

En estos dos pasajes que acabamos de ver el testimonio de la tradición indirecta resulta fundamental para el establecimiento del texto; en el primero, el $\mathrm{dlm}$ es modelo de un autor posterior, en el segundo, receptor de una influencia 'clásica'. Las alusiones de este tipo, que de forma tácita menudean en los autores latinos, sobre todo en el período tardío, constituyen para la crítica textual un material precioso, aunque difícil de desentrañar.

Manuscritos citados:

S París, Bibliothèque Nationale, lat. 10592 s. VI-VII

L Viena, Österreichische Nationalbibliothek, Lat. 962 s. IX

N Monte Cassino, Biblioteca dell'Abbazia 204 s. X

$\mathrm{P}$ París, Bibliothèque Nationale, lat. 1647 A s. IX

M Munich, Staatsbibliothek, Clm 208s. IX

Q Troyes, Bibliothèque Municipale, 581 s. VIII-IX

T Vaticano, Regin. lat. 118 s. IX

126b Metz, Bibliothèque Municipale, 224 s. XI 


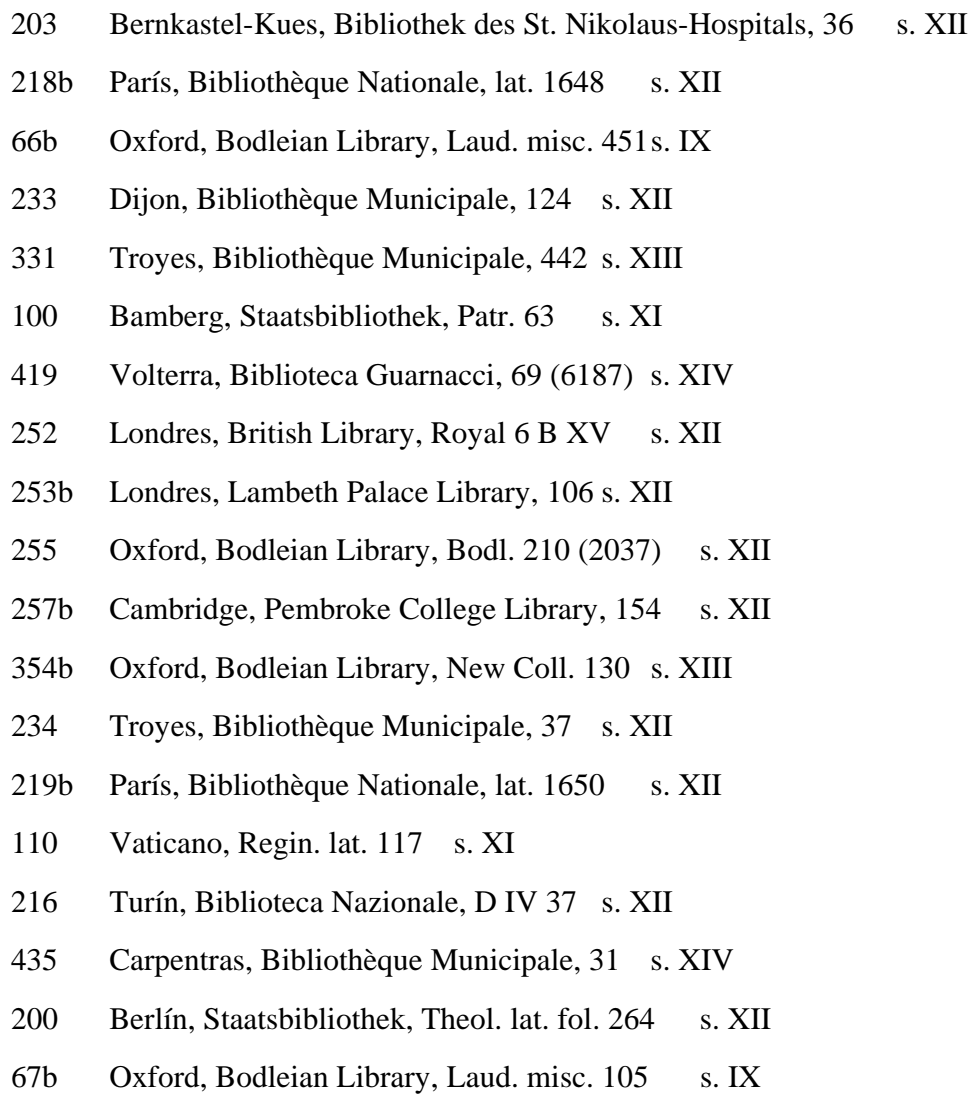

